\title{
Acute-onset floaters and flashes
}

\author{
Davin Johnson MD, Hussein Hollands MD MSc
}

\section{Posterior vitreous detachment is a common age-related condition typi- cally presenting as acute-onset floaters and flashes of light}

Posterior vitreous detachment is the most common cause of acute-onset floaters or flashes of light. Its prevalence is $24 \%$ among adults aged $50-59$ years, increasing to $87 \%$ among people older than 80 years. ${ }^{1}$

\section{Patients presenting with likely posterior vitreous detachment should be referred to an ophthal- mologist to exclude a retinal tear or detachment}

The acute onset of floaters or flashes of light is often secondary to posterior vitreous detachment; however, the differential diagnosis also includes migraine aura (typically binocular symptoms of flashes) and other conditions. Patients with likely posterior vitreous detachment should be referred to an ophalmologist for a complete dilated eye examination with indirect ophthalmoscopy and scleral depression, or contact lens biomicroscopy, to exclude a retinal tear or detachment. Because most retinal tears are found peripherally, direct ophthalmoscopy alone is insufficient.

\section{Posterior vitreous detachment, retinal tear and retinal detachment are a spectrum of disease}

In posterior vitreous detachment, the vitreous shrinks and detaches from the retina leading to symptoms of floaters and/or flashes. In $14 \%$ of cases, tractional forces from the vitreous jelly on the retina cause a full-thickness retinal tear. ${ }^{2}$ Left untreated, retinal tears allow fluid to enter the subretinal space (between the retina and choroid) and can progress to a retinal detachment and possible blindness (see image in Appendix 1, available at www.cmaj.ca/lookup/suppl/doi:10 .1503/cmaj.110686/-/DC1.

\section{Physicians can identify "high-risk" features that warrant urgent referral}

A recent meta-analysis supports sameday referral for any patient with acute onset of floaters or flashes of light and a defect in their visual field ("curtain of darkness"). ${ }^{2}$ Subjective visual reduction (likelihood ratio [LR] 5.0, 95\% confidence interval [CI] 3.1-8.1) or the presence of vitreous hemorrhage (LR 10, 95\% CI 5.1-20) or pigment (LR 44, 95\% CI 2.3-852) suggest increased risk of retinal tear. ${ }^{2}$ Patients with these symptoms require referral within 24 hours. ${ }^{2}$ Both vitreous hemorrhage and vitreous pigment can be seen with a slit lamp focused on the anterior vitreous. Patients with acute onset of floaters or flashes of light but no defect in their visual field should be seen within one week. ${ }^{2}$
Uncomplicated posterior vitreous detachment may develop into a retinal tear within six weeks

Patients with uncomplicated posterior vitreous detachment should be re-examined by an ophthalmologist at six weeks, as $3.4 \%$ will have a new retinal tear. ${ }^{3}$ Clues to the presence of such tears include a new shower of floaters or subjective visual reduction. Patients with these symptoms should be re-examined sooner.

\section{References}

1. Hikichi T, Hirokawa H, Kado M, et al. Comparison of the prevalence of posterior vitreous detachment in whites and Japanese. Ophthalmic Surg 1995;26: $39-43$.

2. Hollands H, Johnson D, Brox AC, et al. Acuteonset floaters and flashes: Is this patient at risk for retinal detachment? JAMA 2009;302:2243-9.

3. Dayan MR, Jayamanne DG, Andrews RM, et al Flashes and floaters as predictors of vitreoretinal pathology: Is follow-up necessary for posterior vitreous detachment? Eye (Lond) 1996;10:456-8.

\section{Competing interests: None declared.}

This article has been peer reviewed.

Affiliations: From the Department of Ophthalmology (Johnson), Queen's University, Kingston, Ont.; and the Department of Ophthalmology (Hollands), University of Toronto, Toronto, Ont.

CMAJ invites submissions to "Five things to know about ..." Submit manuscripts online at http://mc.manuscriptcentral .com/cmaj 